Check for updates

Cite this: RSC Adv., 2017, 7, 39063

Received 24th May 2017

Accepted 24th July 2017

DOI: 10.1039/c7ra05825j

rsc.li/rsc-advances

\section{Pyridine-based functionalized graphene oxides as a new class of corrosion inhibitors for mild steel: an experimental and DFT approach $\dagger$}

\author{
Rajeev Kumar Gupta, ${ }^{a}$ Manisha Malviya, ${ }^{a}$ Chandrabhan Verma, ${ }^{\text {ab }}$ Neeraj K. Gupta ${ }^{a}$ \\ and M. A. Quraishi (D)*ac
}

\begin{abstract}
The aims of the present work were to synthesise two functionalized graphene oxides, namely, diazo pyridine functionalized graphene oxide (DAZP-GO) and diamino pyridine functionalized graphene oxide (DAMP-GO), and to evaluate them as corrosion inhibitors on mild steel in $1 \mathrm{M}$ hydrochloric acid. Electrochemical studies reveal that the inhibition efficiencies of both of the tested functionalized graphene oxides were enhanced with increasing concentration and the maximum inhibition efficiencies of $95.08 \%$ and $96.73 \%$ were obtained for DAMP-GO and DAZP-GO, respectively, at a concentration as low as $25 \mathrm{mg} \mathrm{L}^{-1}$. A potentiodynamic polarization study suggests that both DAZP-GO and DAMP-GO act as mixed type inhibitors with a slight cathodic predominance. The formation of a protective film on the mild steel surface was confirmed using scanning electron microscope, energy dispersive $X$-ray spectroscopy, atomic force microscopy and $X$-ray photoelectron spectroscopy techniques. Dynamic functional theory parameters such as $E_{\mathrm{HOMO}}, E_{\mathrm{LUMO}}$, energy band gap $(\Delta E)$, electronegativity $(\chi)$, hardness $(\eta)$, softness $(\sigma)$ and a fraction of electron transfer $(\Delta N)$ were calculated to support the experimental results.
\end{abstract}

\section{Introduction}

Corrosion is a destructive phenomenon that results in huge economic losses and many safety issues. ${ }^{\mathbf{1 - 3}}$ The global cost of corrosion is estimated to be $\$ 2.5$ trillion (USD) which is approximately equivalent to $3.4 \%$ of the total Gross Domestic Product (GDP). ${ }^{4,5}$ A significant amount of this cost, approximately $15-35 \%$, could be avoided by implementing suitable anti-corrosion technology. Among the available methods of corrosion control, the use of corrosion inhibitors is one of the most popular methods because of its cost-effectiveness and ease of application. ${ }^{6,7}$ Organic compounds with heteroatoms have been reported as potential corrosion inhibitors for metallic corrosion. ${ }^{8-10}$ However, because of their toxicity and thermal instability in an acid medium, they are not very useful for practical applications. ${ }^{11-13}$

Recently graphene derivatives have been reported as anticorrosive coating materials for marine and other corrosive environments because of their various unique properties such

\footnotetext{
${ }^{a}$ Department of Chemistry, Indian Institute of Technology, Banaras Hindu University, Varanasi 221005, India. E-mail: maquraishi.apc@itbhu.ac.in; Fax: +91-542-2368428; Tel: +91-9307025126

${ }^{b}$ Department of Chemistry, Faculty of Agriculture, Science and Technology, North-West University, Mafikeng Campus, Private Bag X2046, Mmabatho 2735, South Africa ${ }^{c}$ Center of Research Excellence in Corrosion, Research Institute, King Fahd University of Petroleum \& Minerals, Dhahran 31261, Saudi Arabia

† Electronic supplementary information (ESI) available. See DOI: 10.1039/c7ra05825j
}

as high surface area, chemical resistance, thermal and electrical conductivity, enhanced mechanical strength, high level of impermeability and hydrophobicity. ${ }^{\mathbf{1 4 - 2 1}}$ It is documented in the literature that the graphene is insoluble in an aqueous medium because of the lack of functional groups and therefore they are used as anti-coating materials only. ${ }^{15,16}$ However, graphene oxide (GO) and functionalized GOs could act as good corrosion inhibitors in the solution phase because of the presence of various oxygen (O)-containing functional groups such as hydroxyls, epoxides, carboxyl and carbonyl on their surfaces. ${ }^{17-19}$ In view of this observation, two functionalized GOs were synthesized, diazo pyridine functionalized graphene oxide (DAZP-GO) and diamino pyridine functionalized graphene oxide (DAMP-GO), to study their corrosion inhibition behavior on mild steel in $1 \mathrm{M}$ hydrochloric acid $(\mathrm{HCl})$ solution using experimental and dynamic functional theory (DFT) methods.

\section{Experimental sections}

\subsection{Chemicals}

The following chemicals were used in the present study: 2,6diaminopyridine (DAP; Sigma-Aldrich), sodium hydroxide $\left(\mathrm{NaOH} ; \mathrm{SD}\right.$ Fine Chemicals Ltd.), sodium nitrite $\left(\mathrm{NaNO}_{2}\right.$; Merck), crystalline graphite powder (Alfa Aesar), sodium chloride (Merck), hydrogen peroxide (30\%, Merck), concentrated sulfuric acid (Merck, 98\% pure), potassium permanganate (Merck), methanol (99.9\%, Merck), $\mathrm{HCl}$ (35\%, Merck) and double distilled water. 


\subsection{Procedure for synthesis of inhibitors}

2.2.1. Synthesis of diaminopyridine functionalized graphene oxide (DAMP-GO). In the present investigation, GO was synthesized using crystalline graphite powder and the modified Hummers' method.22 For synthesizing the DAMP-GO composite, GO solution $(10 \mathrm{~mL})$ was dissolved in double distilled water $(100 \mathrm{~mL})$, and then mixed ultrasonically for $1 \mathrm{~h}$ to obtain a homogeneous solution. To this solution, $500 \mathrm{mg}$ of DAP was added at $50{ }^{\circ} \mathrm{C}$ for $1 \mathrm{~h}$, and then mixed ultrasonically for $90 \mathrm{~min}$ and then the temperature was gradually elevated to $80{ }^{\circ} \mathrm{C}$ with constant stirring for $4 \mathrm{~h}$. The crude product was purified using filtration, and the residue was washed with copious amounts of water, ethanol and finally dried under vacuum at $60{ }^{\circ} \mathrm{C}$ for $24 \mathrm{~h} . .^{22,23}$

2.2.2. Synthesis of diazopyridine functionalized graphene oxide (DAZP-GO). Synthesis of DAZP-GO involved two-steps, firstly diazotization was performed followed by the coupling of the diazopyridine compound with GO. For the diazotization, DAP (500 mg) was dissolved in $2 \mathrm{~mL}$ of distilled water at $50{ }^{\circ} \mathrm{C}$ and concentrated $\mathrm{HCl}(35 \%, 2 \mathrm{~mL})$ was added dropwise under constant stirring to obtain a clear solution. The resulting solution was cooled to $2{ }^{\circ} \mathrm{C}$, and $\mathrm{NaNO}_{2}$ solution $(420 \mathrm{mg}, 2 \mathrm{~mL})$ was added dropwise (to keep the temperature at $2{ }^{\circ} \mathrm{C}$ ) ${ }^{\mathbf{2 4 , 2 5}}$ In order to complete the diazotization process, the resulting mixture was stirred at $2{ }^{\circ} \mathrm{C}$ for $1 \mathrm{~h}$, and then urea was added to this mixture to remove the excess nitrous acid $\left(\mathrm{HNO}_{2}\right)$.

For the coupling of diazopyridine with GO, a homogenous solution of GO in $10 \mathrm{~mL}$ of water was made by mixing the solution ultrasonically for $1 \mathrm{~h}$. To this solution, $25 \mathrm{~mL}$ of $2 \%$ $\mathrm{NaOH}$ was added dropwise and then stirred for $2 \mathrm{~h}$. To this solution, diazonium salt solution was added dropwise at such a rate that the $\mathrm{pH}$ of the resulting solution remained constant at 9 and the temperature of the solution did not exceed $2{ }^{\circ} \mathrm{C}$. After the reaction was complete, the $\mathrm{pH}$ of the reaction mixture was reduced to 7 and the crude product was then washed with double distilled water, methanol and dried at $80{ }^{\circ} \mathrm{C}$ under vacuum..$^{2,25}$ Scheme 1 shows the synthesis of functionalized GOs.

\subsection{Materials and measurements}

2.3.1. Materials. The working electrode used in all the experiments were performed with the mild steel specimens with a composition (wt\%) of: carbon (C, 0.076), phosphorus (0.012), manganese (0.192), chromium (0.050), silica (0.026), aluminum (0.023), and iron (Fe, 99.41). The test solution was prepared by diluting analytical grade $\mathrm{HCl}$ (AR grade; 37\% from Merck) in double deionized water. Before the experiments, these specimens were abraded with emery paper of several grades (6001200 mesh size), washed with water, degreased (in acetone), dried in a hot air oven and stored in moisture free desiccators.

2.3.2. Physicochemical measurements. The synthesized GOs and their composites were characterized using powder Xray diffraction (XRD) measurements with a Rigaku highresolution (HR)-XRD (SmartLab, $9 \mathrm{~kW}$ power) with $\mathrm{Cu} \mathrm{K}_{\alpha}$ radiation $(\lambda=1.5406 \AA)$ and a nickel filter. Fourier transforminfrared (FT-IR) spectroscopic measurements were made using a PerkinElmer spectrometer (Spectrum 100). Raman spectra were obtained with a Renishaw confocal Raman spectrometer (inVia) equipped with a diode pumped solid state laser of wavelength $532 \mathrm{~nm}$. The Raman scattered light was collected using backscattering geometry with a slit width of $50 \mathrm{~mm}$. X-ray photoelectron spectroscopy (XPS) analysis was carried out, using $\mathrm{Mg} \mathrm{K} \alpha(1253.6 \mathrm{eV})$ radiation as the source of the X-rays, with a Kratos Analytical spectrometer (Amicus).

2.3.3. Electrochemical measurements. The electrochemical analysis was performed using the Gamry Potentiostat/ Galvanostat (Series G 300) which consists of the Gamry Echem Analyst 5.0 software for fitting, simulating and analyzing the Nyquist plots. Similar to our previous investigations, ${ }^{\mathbf{2 6 , 2 7}}$ the mild steel specimens with exposed area of $1 \mathrm{~cm}^{2}$, saturated calomel and pure platinum were as working electrode (WE), reference electrode (RE) and counter electrode (CE), respectively for all electrochemical measurements. All the electrochemical measurements were performed in triplicate in order to ensure the reproducibility of the results. The experiments were carried out after $30 \mathrm{~min}$ immersion time in order to establish the open circuit potential. A potentiodynamic polarization study was carried out by recording the Tafel slopes in the absence and presence of several concentrations of both inhibitors by varying the WE potentials from -0.25 to $+0.25 \mathrm{~V}$ versus the corrosion potential $\left(E_{\text {corr }}\right)$ at a continual sweep rate of $1.0 \mathrm{mV} \mathrm{s}^{-1}$. These Tafel slopes were extrapolated to derive corrosion current densities $\left(i_{\text {corr }}\right)$ for inhibited and uninhibited metallic specimens. The inhibition efficiency at different concentrations of inhibitors was determined using relationships given next: ${ }^{26,27}$

$$
\eta \%=\frac{i_{\text {corr }}^{0}-i_{\text {corr }}^{\mathrm{i}}}{i_{\text {corr }}^{0}} \times 100
$$

where, $i_{\text {corr }}^{0}$ and $i_{\text {corr }}^{\mathrm{i}}$ represent corrosion current densities without and with inhibitors, respectively. The electrochemical impedance spectroscopy (EIS) measurements were carried out in the frequency range of $100 \mathrm{kHz}$ to $0.01 \mathrm{~Hz}$ by using $\mathrm{AC}$ having an amplitude of $10 \mathrm{mV}$ peak to peak. The Nyquist plots of inhibited and uninhibited specimens were fitted to a suitable circuit to obtain charge transfer resistance and using that, the percentage inhibition $(\eta \%)$ performance was calculated as follows: $:^{26,27}$

$$
\eta \%=\frac{R_{\mathrm{ct}}^{\mathrm{i}}-R_{\mathrm{ct}}^{0}}{R_{\mathrm{ct}}^{\mathrm{i}}} \times 100
$$

where, $R_{\mathrm{ct}}^{0}$ and $R_{\mathrm{ct}}^{\mathrm{i}}$ represent transfer resistances for uninhibited and inhibited metallic specimens, respectively.

2.3.4. Surface measurements. The properly cleaned metallic specimens were permitted to corrode for $3 \mathrm{~h}$ in the absence and presence of an optimum concentration of both of the inhibitors before scanning electron microscopy-energy dispersive X-ray spectroscopy (SEM-EDX) and atomic force microscopy (AFM) analyses were carried out. After $3 \mathrm{~h}$, the specimens were washed with double distilled water, dried in a hot air oven and finally analyzed using SEM-EDX and AFM methods. The SEM-EDX analyses were carried out using a Carl Zeiss SEM (Evo $50 \mathrm{XVP}$ ) instrument at 500× magnification, whereas, the atomic force microscopy (AFM) was performed 


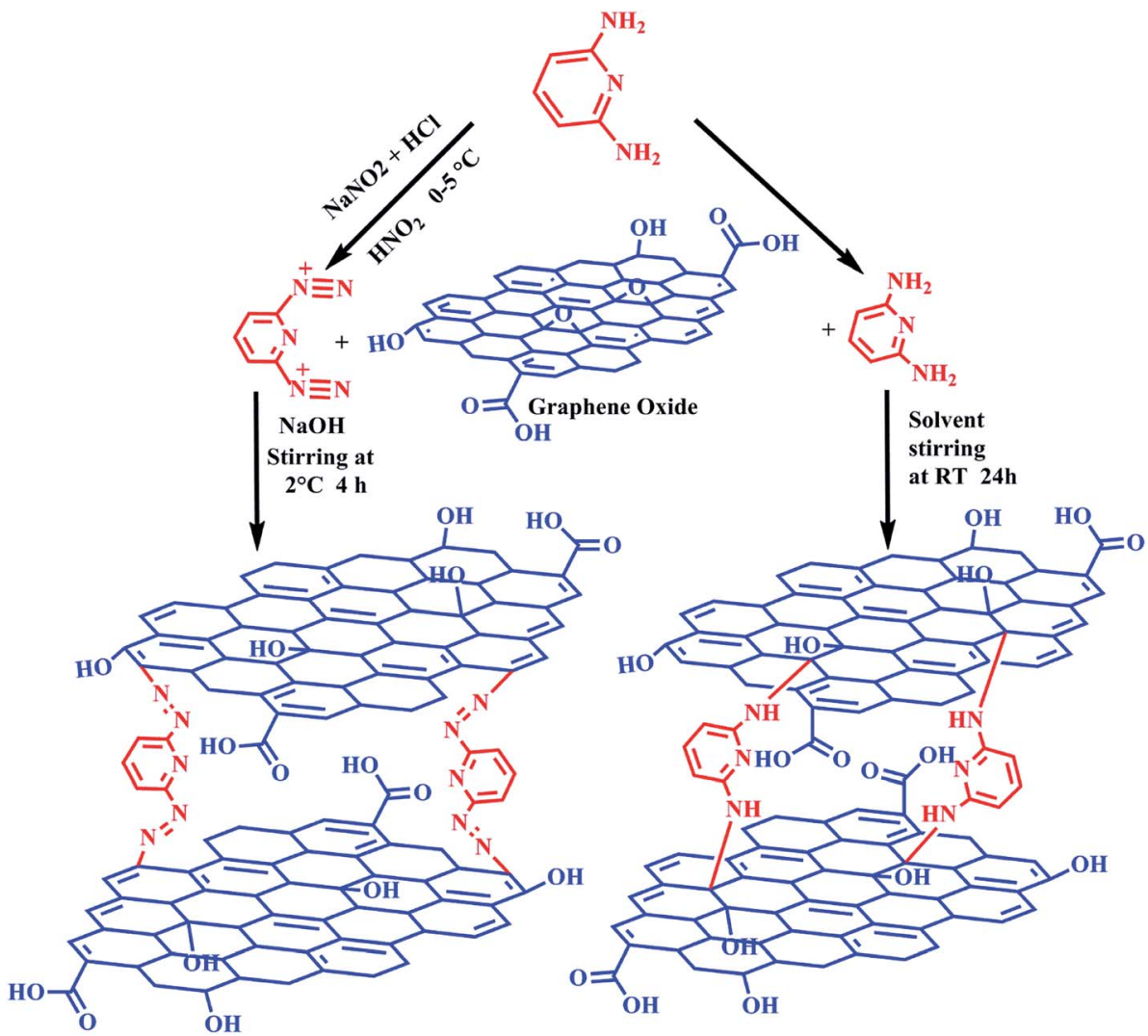

Scheme 1 Synthesis of the inhibitors to be investigated.

using a NT-MDT multimode AFM (Russia) controlled by a solver scanning probe microscope controller. The instrument consists of a single beam cantilever that has a resonance frequency between 240 and $255 \mathrm{kHz}$ under semi-contact mode together with a corresponding spring constant of $11.5 \mathrm{~N} \mathrm{~m}^{-1}$. The instrument contains NOVA software which was used for image elucidation. A scanning area of $5 \mu \mathrm{m} \times 5 \mu \mathrm{m}$ was used during the AFM analysis.

2.3.5. Computational measurements. The quantum chemical calculations were performed using Gaussian 09 software, as described previously in various papers in the literature. ${ }^{28-32}$ The optimized structures of both the basic ligands were obtained using the B3LYP/6-31G (d) model of the DFT method. According to several highly cited papers, the value of energy of the highest occupied molecular orbital $\left(E_{\text {номо }}\right)$ and the energy of the lowest unoccupied molecular orbital ( $\left.E_{\text {LUMO }}\right)$ correspond to the ionization potential $(I)$ and electron affinity $(A)$ as shown by eqn (3) and (4). Several quantum chemical calculation indices based on energies of frontier molecular orbitals $\left(E_{\text {Номо }}\right.$ and $\left.E_{\text {LUMO }}\right)$ were obtained using the following relationships:

$$
\begin{gathered}
I=-E_{\text {Номо }} \\
A=E_{\mathrm{LUMO}} \\
\eta=\frac{E_{\mathrm{LUMO}}-E_{\mathrm{HOMO}}}{2}=\frac{\Delta E}{2}
\end{gathered}
$$

$$
\begin{gathered}
\sigma=\frac{1}{\eta} \\
\Delta E=E_{\mathrm{LUMO}}-E_{\mathrm{HOMO}} \\
\chi=-\frac{1}{2}\left(E_{\mathrm{LUMO}}+E_{\mathrm{HOMO}}\right) \\
\Delta N=\frac{\chi_{\mathrm{Fe}}-\chi_{\mathrm{inh}}}{2\left(\eta_{\mathrm{Fe}}+\eta_{\mathrm{inh}}\right)}
\end{gathered}
$$

In the previous equations, $E_{\mathrm{HOMO}}$ and $E_{\mathrm{LUMO}}$ represent energies of highest occupied molecular orbital and lowest unoccupied molecular orbital, respectively, $I$ is the ionization potential, $A$ is the electron affinity, $\Delta E$ is the energy band gap, $\eta$ is the hardness, $\sigma$ is the softness, $\chi$ is the global electronegativity, and $\Delta N$ is the fraction of electron transfer. A value of $7.0 \mathrm{eV}$ was used for the $\chi_{\mathrm{Fe}}$, whereas $\eta_{\mathrm{Fe}}$ was taken as $0 \mathrm{eV}$ for bulk $\mathrm{Fe}$ atoms in accordance with the Pearson's electronegativity scale.

\section{Results and discussion}

\subsection{Characterization of the inhibitors}

The synthesis of GO and its functionalization with diaminopyridine (DAMP-GO) and diazopyridine (DAZP-GO) was confirmed using FT-IR. Fig. 1(a) shows the FT-IR spectra for GO 

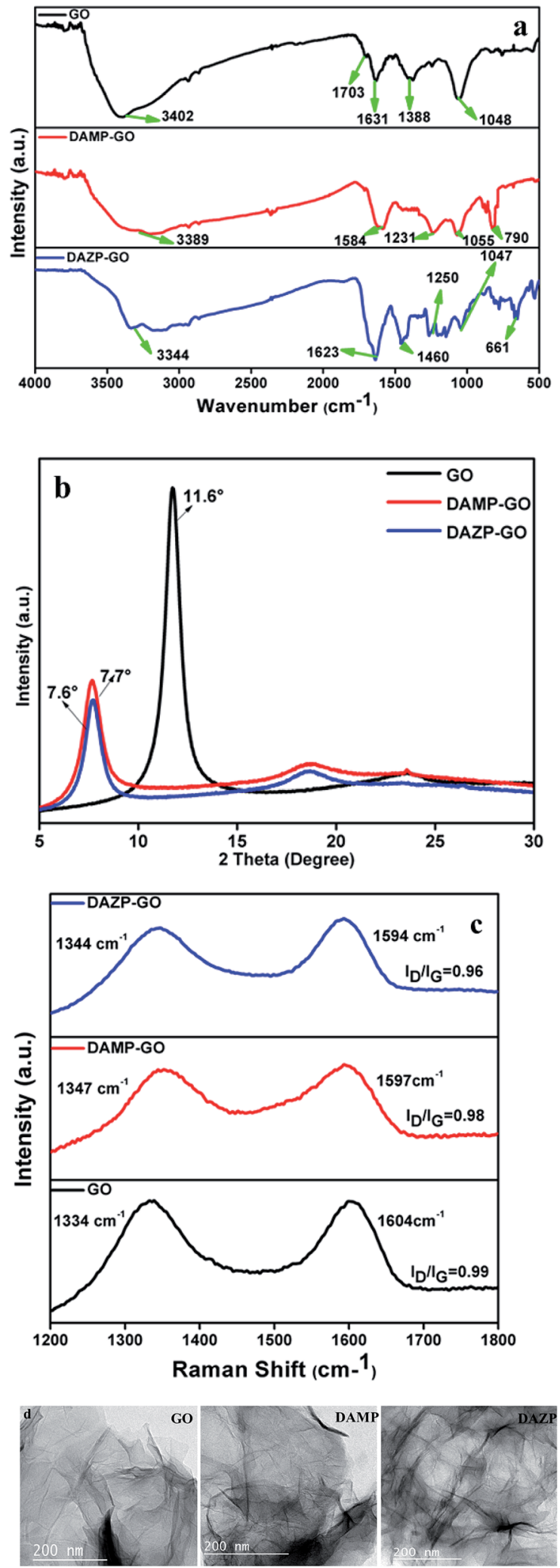

Fig. 1 (a) FT-IR spectra of synthesized GO, DAMP-GO and DAZP-GO composites; (b) XRD peaks of synthesized GO, DAMP-GO and DAZPGO composites; (c) Raman spectra of synthesized GO, DAMP-GO and DAZP-GO composites; (d) TEM images of the GO, DAMP-GO and DAZP-GO composite material showing a layered-type structure. and DAMP-GO and DAZP-GO. For pure GO, the peaks at 3402, $1703,1631,1388$, and $1048 \mathrm{~cm}^{-1}$ occur because of the $\nu_{\mathrm{s}}(\mathrm{O}-\mathrm{H})$, $\nu_{\mathrm{s}}(\mathrm{C}=\mathrm{O}), \nu_{\mathrm{s}}(\mathrm{C}=\mathrm{C}), \nu_{\mathrm{b}}(\mathrm{O}-\mathrm{H}), \nu_{\mathrm{s}}(\mathrm{C}-\mathrm{O})$ of the epoxides $\nu_{\mathrm{s}}(\mathrm{C}-\mathrm{O}-\mathrm{C})$, respectively. ${ }^{22,24}$ The broad peak in the region centered at 3500 $\mathrm{cm}^{-1}$ to $3000 \mathrm{~cm}^{-1}$ in DAMP-GO and DAZP-GO composites confirms the presence of $-\mathrm{OH}$ and $-\mathrm{NH}$ groups. The presence of the benzene ring is confirmed by the peak between 1633 and $1499 \mathrm{~cm}^{-1}$ occurring because of the $\nu_{\mathrm{s}}(\mathrm{C}=\mathrm{C})$ in the benzene ring. In the DAZP-GO composites, the presence of the azo $(-\mathrm{N}=$ $\mathrm{N}-$ ) group is confirmed by a peak at $1460 \mathrm{~cm}^{-1}$ which occurs because of the $\nu_{\mathrm{S}}(\mathrm{N}=\mathrm{N}) \cdot{ }^{24,25}$ In both DAMP-GO and DAZP-GO composites, the $\nu_{\mathrm{s}}(\mathrm{C}-\mathrm{N})$ peaks between 1277 and $1210 \mathrm{~cm}^{-1}$ are observed. Also, the band at $1055 \mathrm{~cm}^{-1}$ represents the $\mathrm{C}-\mathrm{O}$ group. The breaking of the epoxy bonds because of the addition of alkali is confirmed by the $\nu_{\mathrm{s}}(\mathrm{C}-\mathrm{O})$ of the epoxides $(\mathrm{C}-\mathrm{O}-\mathrm{C}){ }^{23}$ All these peaks and the other peaks in the region $800-650 \mathrm{~cm}^{-1}$ confirm the formation of the DAMP-GO and DAZP-GO composites..$^{22-24}$

XRD results likewise confirm the formation of GO and its functionalized composite with diaminopyridine (DAMP-GO) and diazopyridine (DAZP-GO). The acquired XRD patterns of GO and DAMP, DAZP functionalized GO are presented in the Fig. 1(b). Diffraction peaks seen at a $2 \theta$ value of $11.6^{\circ}$ in the XRD pattern of GO arise because of the diffraction from the different oxygen containing functional group on the sides of the sheets. ${ }^{22}$ After covalently bonding DAMP and DAZP with GO, the XRD peak of GO was observed to shift to the lower $2 \theta$ value of 7.6 in the DAMP-GO and DAZP-GO. The decrease in the XRD pattern occurs because of the expansion in the interlayer spacing in the presence of a ligand (DAMP and DAZP) in the GO sheets. A similar shift in the XRD pattern has been observed. ${ }^{22}$ The reduced intensity of peaks in pure GO and functionalized GO indicates that exfoliation occurs during the ultrasonic mixing.

The data obtained from Raman spectra shown in Fig. 1(c) further support the formation of DAMP-GO and DAZP-GO. The Raman spectra of GO shows the presence of a $\mathrm{G}$ peak $\left(\mathrm{sp}^{2}\right)$ hybridized carbon atom at $1604 \mathrm{~cm}^{-1}$ and a D peak $\left(\mathrm{sp}^{3}\right)$ hybridized carbon atom at $1334 \mathrm{~cm}^{-1}$. The functionalized GO shows shifting of these peaks which represents surface modification by incorporation of ligands (DAZP and DAMP) and the ratio of the intensity of the D-Raman peak and the G-Raman peak $\left(I_{\mathrm{D}} / I_{\mathrm{G}}\right)$ ratio of DAMP-GO and DAZP-GO were found to be 0.98 and 0.96 , respectively, which is smaller than that of GO $(\sim 0.99)$. These observations support a percentage increment in $\mathrm{sp}^{2}$ carbon atoms in functionalized GOs which is caused by nucleophilic addition of the azo and amino groups of DAZP and DAMP to GO molecules and also supports the formation of covalent bonds. A similar explanation has been given for GO and functionalized GO by Gupta et al. ${ }^{22,24}$ and Singh et al. ${ }^{33}$

The transmission electron microscopy (TEM) images shown in Fig. 1(d) were used to characterize the GO, DAMP-GO, and DAZP-GO. The TEM images of GO indicate that there is typically two to three layers of GO. After the functionalization with DAMP and DAZP ligands, the GO layers are stacked together to form a composite structure, and the surface becomes very rough which is shown in Fig. 1(d) (DAMP-GO and DAZP-GO). This 
crosslinking of GO layers resulting from functionalization by ligands has also been reported by Gupta et al. ${ }^{22,24}$

XPS was utilized to determine the binding energies of various functional groups in GO, DAMP-GO and DAZP-GO composites. The XPS pattern of GO, the core-level photoemission peaks [Fig. 2(a)] show the presence of only $\mathrm{C}$ and $\mathrm{O} 1 \mathrm{~s}$ orbitals. The high-resolution carbon 1s XPS spectrum of GO [Fig. 2(b)] shows three peaks at 285.1, 286.4, and $287.9 \mathrm{eV}$, corresponding to $\mathrm{C}-\mathrm{C}, \mathrm{C}-\mathrm{O}$ (hydroxyl and epoxide), and $\mathrm{C}=\mathrm{O}$ (carboxyl) groups of GO, respectively. The XPS pattern of the DAMP-GO composite [Fig. 2(c)] indicates the characteristic C 1s, $\mathrm{N} 1 \mathrm{~s}$, and $\mathrm{O} 1 \mathrm{~s}$ centered photoemission signals at $\sim 286, \sim 401.5$ and $\sim 534 \mathrm{eV}$, respectively. ${ }^{22}$ The high-resolution $\mathrm{C}$ 1s XPS spectrum of the DAMP-GO composite shown in Fig. 2(d) is conveniently fitted using five components. The first peak at 284.9 is ascribed to the $\mathrm{C}-\mathrm{C}$ bond in graphene and its analogs. Likewise, the peaks at 285.4 and 286.0 arise from the $\mathrm{C}-\mathrm{N}$ and $-\mathrm{C}=\mathrm{N}$ bonds, respectively. Another peak at 286.6 represents the $\mathrm{C}-\mathrm{O}$ bonds and the maximum binding energy peak at 287.5, occurs because of the carboxylic groups. In order to understand the chemical character of nitrogen (N) in the DAMP-GO, it is important to know the nature of the interaction between the GO sheet and the nitrogen containing functional group in DAMPGO. Fig. 2(e) shows a high-resolution $\mathrm{N}$ 1s XPS spectrum, which was fitted with three peaks. The lower segment at 399.3 is ascribed to the $-\mathrm{C}=\mathrm{N}$ bond of diaminopyridine and a middle segment comprises of the peak at 400.2 and indicates the presence of the amine group. This peak confirms the grafting of the amino group in DAMP with a GO skeleton. The third segment consists of the peak with the maximum binding energy at 401.03 and this occurs because of the protonated amino group in the DAMP-GO framework. ${ }^{22}$

The XPS [Fig. 2(f)] of the DAZP-GO composite at $\sim 285, \sim 401$, and $\sim 534 \mathrm{eV}$ emerges because of photoemission from the $1 \mathrm{~s}$ orbital of $\mathrm{C}, \mathrm{N}$, and $\mathrm{O}$, respectively. ${ }^{24}$ The highly resolved $\mathrm{C} 1 \mathrm{~s}$ XPS composite represented in Fig. $2(\mathrm{~g})$ consists of four parts. The minima and the maxima at 284.8 and 288.0 occur because of the presence of the $\mathrm{C}-\mathrm{C}$ bond and a carboxyl group in the
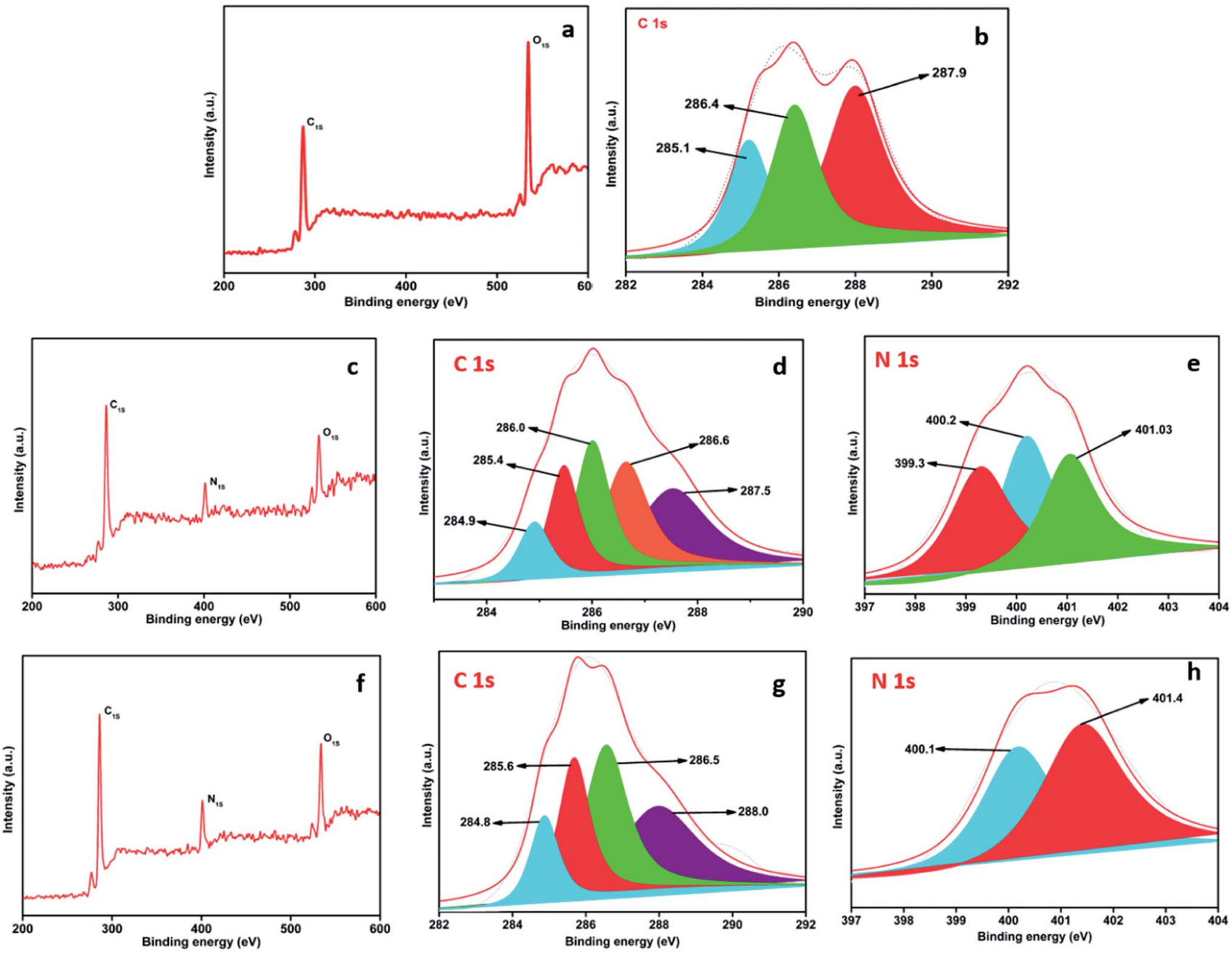

Fig. 2 (a) Wide scan spectra of GO, (b) high-resolution XPS peaks for C 1s in GO, (c) wide scan spectra of the DAMP-GO composite, (d) highresolution XPS peaks for $C 1$ s in the DAMP-GO composite, (e) high-resolution XPS peak of N 1s of the DAMP-GO composite, (f) wide scan spectra of the DAZP-GO composite, (g) high-resolution XPS peaks for C 1s in the DAZP-GO composite, (h) high-resolution XPS peak of N 1s of the DAZPGO composite. 
graphitic framework. The intermediate peaks at 285.6 and 286.5 occur as a result of the $\mathrm{C}-\mathrm{O}$ and $\mathrm{C}-\mathrm{N}$ bonds, respectively. Fig. 2(h) represents the high-resolution XPS originating from the $1 \mathrm{~s}$ orbital of $\mathrm{N}$. The peaks at 400.0 and 400.4 represent a composite band occurring because of the combined effect of $\mathrm{C}-\mathrm{N}$ and the azo group in the DAZP-GO composite. ${ }^{24}$ The previous facts confirm the formation of DAZP-GO and DAMPGO composite structure obtained by interacting GO with DAZP and DAMP atoms as proposed schematically in Scheme 1. The presence of a large number of epoxy and phenolic groups in the GO framework help in the interaction of aryl azo and amino cation with the GO and the formation of the $\mathrm{C}-\mathrm{N}$ bond.

\subsection{Corrosion inhibition studies}

3.2.1. EIS study. Fig. $3(\mathrm{a}$ and $\mathrm{b})$ and $4(\mathrm{a}$ and $\mathrm{b})$ represent the fitted and observed Nyquist plots for uninhibited and inhibited mild steel specimens by DAMP-GO and DAZP-GO in $1 \mathrm{M} \mathrm{HCl}$ and the various EIS parameters such as solution resistance $\left(R_{\mathrm{s}}\right)$, charge transfer resistance $\left(R_{\mathrm{ct}}\right)$, phase shift $(n)$, double and layer capacitance $\left(C_{\mathrm{dl}}\right)$ together with the percentage of inhibition performance $(\eta \%)$. The EIS parameters were derived using the equivalent circuit shown in Fig. 4(c). It can be seen that the Nyquist plots represent a single semicircle whose diameter increases with increasing concentration of the DAMP-GO and DAZP-GO. This finding suggests that the metallic corrosion involves a single charge transfer process and the DAMP-GO and DAZP-GO inhibit corrosion by forming a protective film at the metal surface. ${ }^{34-39}$ In acidic solution, rapid corrosion makes the metallic surface inhomogeneous, and therefore, in the present study constant phase element (CPE) has been used in the place of the pure capacitor. The impedance of the CPE can be represented as follows:

$$
Z_{\mathrm{CPE}}=\left(\frac{1}{Y_{0}}\right)\left[(\mathrm{j} \omega)_{n}\right]^{-1}
$$

where $Y_{0}$ is the CPE constant, commonly known as admittance, $\omega$ is the angular frequency, $n$ is the phase shift, and $\mathrm{j}$ is the imaginary number. The value of $n$ is a measure for surface roughness, in general, a lower value of $n$ is associated with a higher surface roughness and vice versa. Careful observation of the results shown in Table 1 suggests that values of $n$ are higher for inhibited metallic specimens (0.829 to 0.899) when compared to the uninhibited mild steel specimen and this
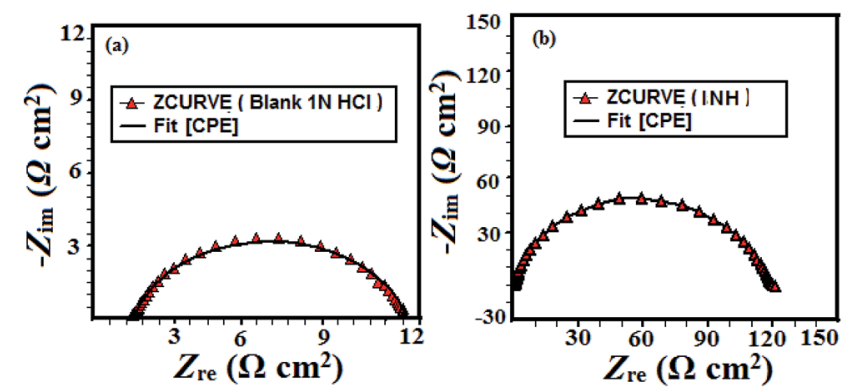

Fig. 3 (a and b) Nyquist plots for mild steel corrosion in $1 \mathrm{M} \mathrm{HCl}$ in the absence and presence of different concentrations of composites, (c) equivalent circuit used for fitting the EIS data. suggests that mild steel surfaces are more smooth in the presence of DAMP-GO and DAZP-GO which is attributed to the formation of a protective film by DAMP-GO and DAZP-GO. The double layer capacitance $\left(C_{\mathrm{dl}}\right)$ value was calculated using following equation:

$$
C_{\mathrm{dl}}=Y_{0}\left(\omega_{\max }\right) n^{-1}
$$

where $\omega_{\max }$ represents the frequency at which the imaginary part of the impedance is maximum $\left(\operatorname{rad~s}^{-1}\right)$. From the results shown in Table 1 it can be seen that values of $R_{\text {ct }}$ increase whereas values of $C_{\mathrm{dl}}$ decrease with concentration which is attributed to the either successive replacement of water molecules from the metal surface and adsorption of DAMP-GO and DAZP-GO at the metal/electrolyte interfaces or because of the
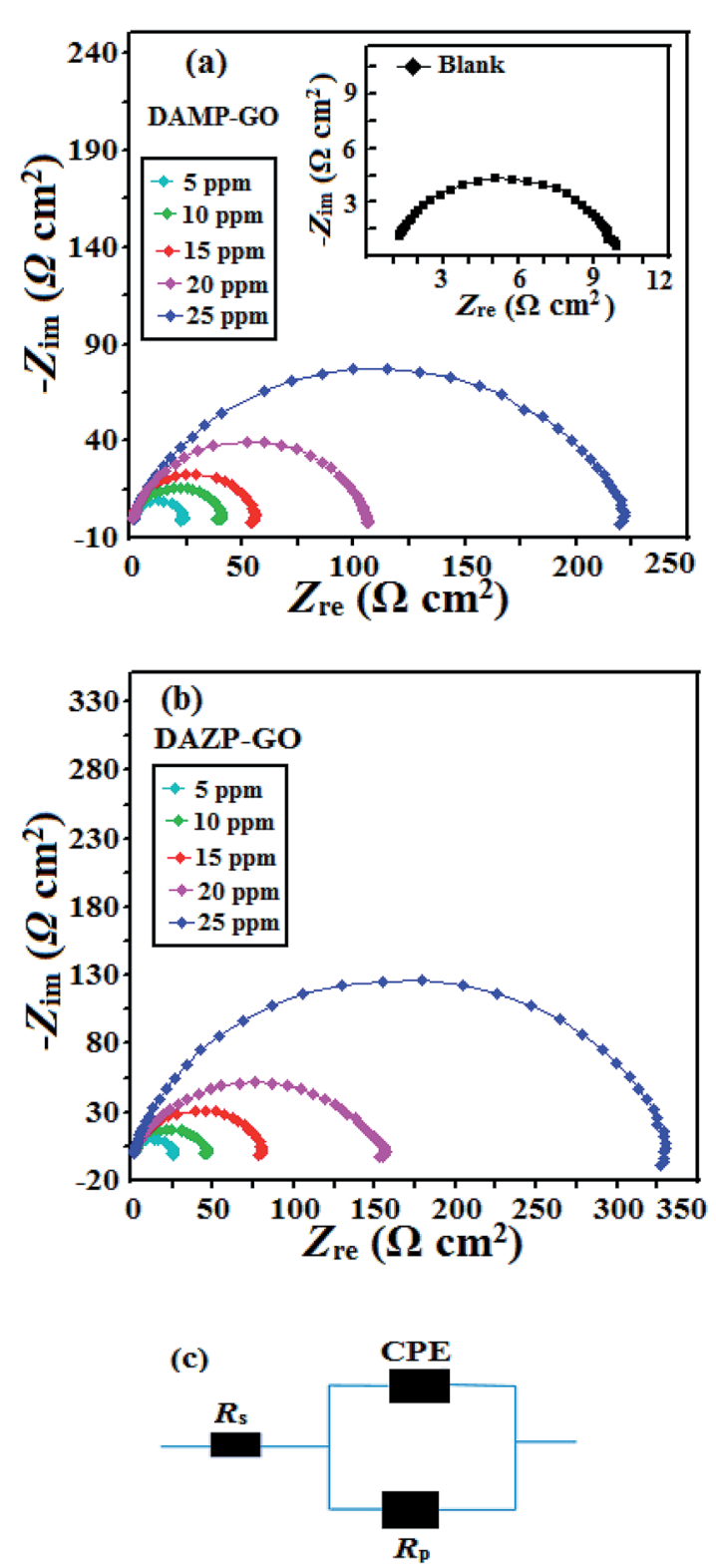

Fig. 4 ( $a$ and b) Nyquist plots for mild steel corrosion in $1 \mathrm{M} \mathrm{HCl}$ in the absence and presence of different concentrations of composites, (c) equivalent circuit used for fitting the EIS data. 
Table 1 EIS parameters for mild steel in $1 \mathrm{M} \mathrm{HCl}$ in the presence and absence of different concentrations of composites

\begin{tabular}{|c|c|c|c|c|c|c|c|c|}
\hline Inhibitor & Conc. $\left(\mathrm{mg} \mathrm{L}^{-1}\right)$ & $R_{\mathrm{S}}\left(\Omega \mathrm{cm}^{2}\right)$ & $R_{\mathrm{p}}\left(\Omega \mathrm{cm}^{2}\right)$ & $n$ & $Y_{0}$ & $C_{\mathrm{dl}}\left(\mu \mathrm{F} \mathrm{cm}^{-2}\right)$ & $\eta \%$ & $\theta$ \\
\hline Blank & - & 1.120 & 9.58 & 0.827 & 482.3 & 138.23 & - & - \\
\hline \multirow[t]{4}{*}{ DAMP-GO } & 5 & 0.129 & 20.86 & 0.868 & 218.5 & 98.35 & 51.69 & 0.5169 \\
\hline & 15 & 1.097 & 54.07 & 0.899 & 80.29 & 44.44 & 80.21 & 0.8021 \\
\hline & 20 & 0.822 & 111 & 0.879 & 85.8 & 43.58 & 90.36 & 0.9036 \\
\hline & 25 & 1.104 & 217.6 & 0.806 & 102.3 & 41.99 & 95.08 & 0.9508 \\
\hline & 15 & 0.800 & 80.10 & 0.849 & 119.6 & 55.36 & 86.64 & 0.8664 \\
\hline & 20 & 0.866 & 151.4 & 0.835 & 97.15 & 41.99 & 92.93 & 0.9293 \\
\hline & 25 & 0.899 & 328.2 & 0.841 & 78.4 & 40.43 & 96.73 & 0.9673 \\
\hline
\end{tabular}

decrease in the value of the dielectric constant and/or because of the combined effect of both. ${ }^{\mathbf{4 0 1}}$ It was further observed that an increase in the value of $R_{\mathrm{ct}}$ is larger in the presence of DAZPGO when compared to DAMP-GO suggesting that DAZP-GO is a better inhibitor than DAMP-GO. It is also important to mention that graphene and GO possess low solubility in polar solvents such as water, methanol, $1 \mathrm{M} \mathrm{HCl}$, and so on because of the presence of their long carbon skeletons. ${ }^{18,20,42}$ However, their functionalization with diazopyridine and diaminopyridine and possibly with other heterocyclic compounds, results in the formation of highly dispersible functionalized GO which can act as efficient inhibitors for mild steel corrosion in a solution phase such as $1 \mathrm{M} \mathrm{HCl}$. The high solubility and anti-corrosive property of these functionalized GO in the present investigation are attributed to the presence of heteroatoms such as $\mathrm{N}, \mathrm{O}$ and the double bond of the azo group $(-\mathrm{N}=\mathrm{N}-)$ which enhance the adsorption tendency of the functionalized GOs.

3.2.2. Potentiodynamic polarization study. Polarization curves for mild steel corrosion with and without inhibitors (DAMP-GO and DAZP-GO) are shown in Fig. 5(a) and (b) and polarization parameters such as current density $\left(i_{\text {corr }}\right)$, corrosion potential $\left(E_{\text {corr }}\right)$, Tafel slopes $\left(\beta_{\mathrm{a}}\right)$ and $\left(\beta_{\mathrm{c}}\right)$ together with percentage inhibition efficiency and surface coverage are presented in Table 2. It can be seen from Fig. 5 that the shapes of the polarization curves are similar for inhibited and uninhibited metallic specimens indicating that both DAMP-GO and DAZP-GO inhibit corrosion simply by blocking the active sites located on the surface without affecting the mechanism of corrosion. ${ }^{\mathbf{4 3 , 4 4}}$ Further, inspection of the results shown in Table 2 reveals that on increasing the concentrations of the inhibitors, values of corrosion current densities $\left(i_{\text {corr }}\right)$ decreased, and the maximum decrease was observed at $25 \mathrm{mg} \mathrm{L}^{-1}$ concentration without causing any substantial change in the value of $E_{\text {corr }}$ indicating that both the inhibitors act as mixed types. However, in the presence of inhibitors, values of cathodic Tafel slopes $\left(\beta_{c}\right)$ are relatively more affected when compared to the values of anodic Tafel slopes $\left(\beta_{\mathrm{a}}\right)$ indicating that both the investigated functionalized GOs act predominantly as a cathodic type. ${ }^{34-36,45}$

\subsubsection{Surface study}

3.2.3.1. SEM-EDX study. The SEM micrographs of the inhibited and uninhibited metallic specimens after $3 \mathrm{~h}$ immersion time are shown in Fig. 6. It can be seen that the surfaces of the inhibited specimens are smoother when compared to the uninhibited specimen. The corresponding EDX spectra of inhibited and uninhibited metallic specimens are shown in Fig. S1 (ESI). $\dagger$ Careful inspection of the EDX spectra reveals that the spectrum of the uninhibited mild steel surface shows signals for the presence of $\mathrm{C}, \mathrm{O}$ and Fe. However,
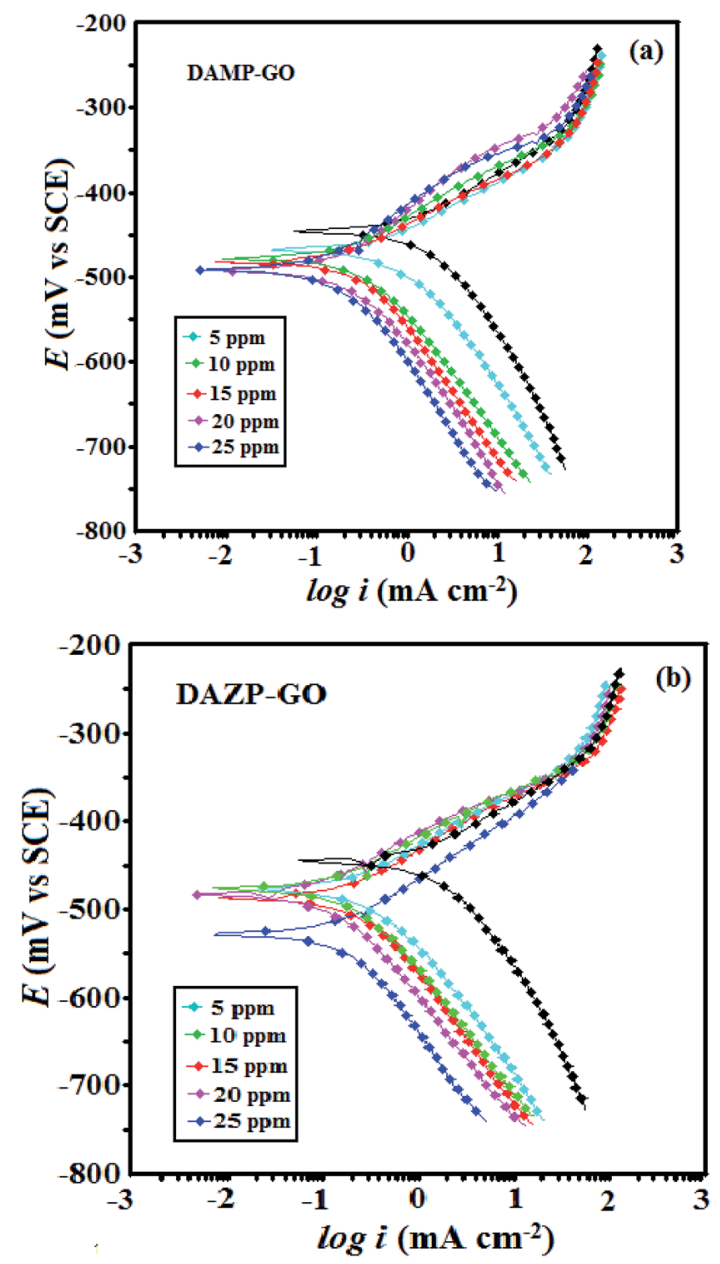

Fig. 5 ( $a$ and b) Potentiodynamic polarization curves for mild steel corrosion in $1 \mathrm{M} \mathrm{HCl}$ in the presence and absence of various concentrations of composites studied. 
Table 2 Tafel parameters for mild steel in $1 \mathrm{M} \mathrm{HCl}$ in the presence and absence of different concentrations of composites

\begin{tabular}{|c|c|c|c|c|c|c|c|}
\hline Inhibitor & Conc. $\left(\mathrm{mol} \mathrm{L}^{-1}\right)$ & $E_{\text {corr }}(\mathrm{mV}$ per SCE $)$ & $\beta_{\mathrm{a}}\left(\mu \mathrm{A} \mathrm{cm}^{-2}\right)$ & $\beta_{\mathrm{c}}\left(\mathrm{mV} \mathrm{dec}{ }^{-1}\right)$ & $i_{\text {corr }}\left(\mathrm{mV} \mathrm{dec}^{-1}\right)$ & $\eta \%$ & $\theta$ \\
\hline Blank & - & -445 & 70.5 & 114.6 & 1150 & - & - \\
\hline \multirow[t]{4}{*}{ DAMP-GO } & 5 & -467 & 73.0 & 119.3 & 552.0 & 52.00 & 0.520 \\
\hline & 15 & -482 & 51.9 & 73.6 & 212.7 & 81.50 & 0.815 \\
\hline & 20 & -492 & 105.2 & 122.9 & 101.2 & 91.20 & 0.912 \\
\hline & 25 & -491 & 97.4 & 121.4 & 59.8 & 94.80 & 0.948 \\
\hline & 15 & -487 & 58.4 & 77.5 & 147.2 & 87.20 & 0.872 \\
\hline & 20 & -483 & 74.9 & 103.7 & 79.3 & 93.10 & 0.931 \\
\hline & 25 & -528 & 88.1 & 158.0 & 35.6 & 96.90 & 0.969 \\
\hline
\end{tabular}

the EDX spectra of inhibited mild steel specimens showed an additional signal for $\mathrm{N}$ indicating the presence of DAMP-GO and DAZP-GO on the surface which could be possible because of their adsorption on the metallic surface (Table 3).

3.2.3.2. AFM analysis. Fig. 7 shows the AFM micrographs of corroded mild steel surfaces in the presence and absence of $25 \mathrm{mg} \mathrm{L}^{-1}$ concentrations of the DAMP-GO and DAZP-GO. The average surface roughness of the uninhibited metallic specimen was $394 \mathrm{~nm}$. However, in the presence of DAMP-GO and DAZP$\mathrm{GO}$, the surface roughness was reduced to $146 \mathrm{~nm}$ and $84 \mathrm{~nm}$, respectively. Increased surface smoothness for inhibited specimens suggested that the inhibitors had been adsorbed by the metallic surface.

3.2.3.3. XPS analysis after inhibition. The XPS analysis after inhibition was used to study the adsorption of inhibitors on mild steel specimens in the presence of $25 \mathrm{mg} \mathrm{L}^{-1}$ of inhibitor
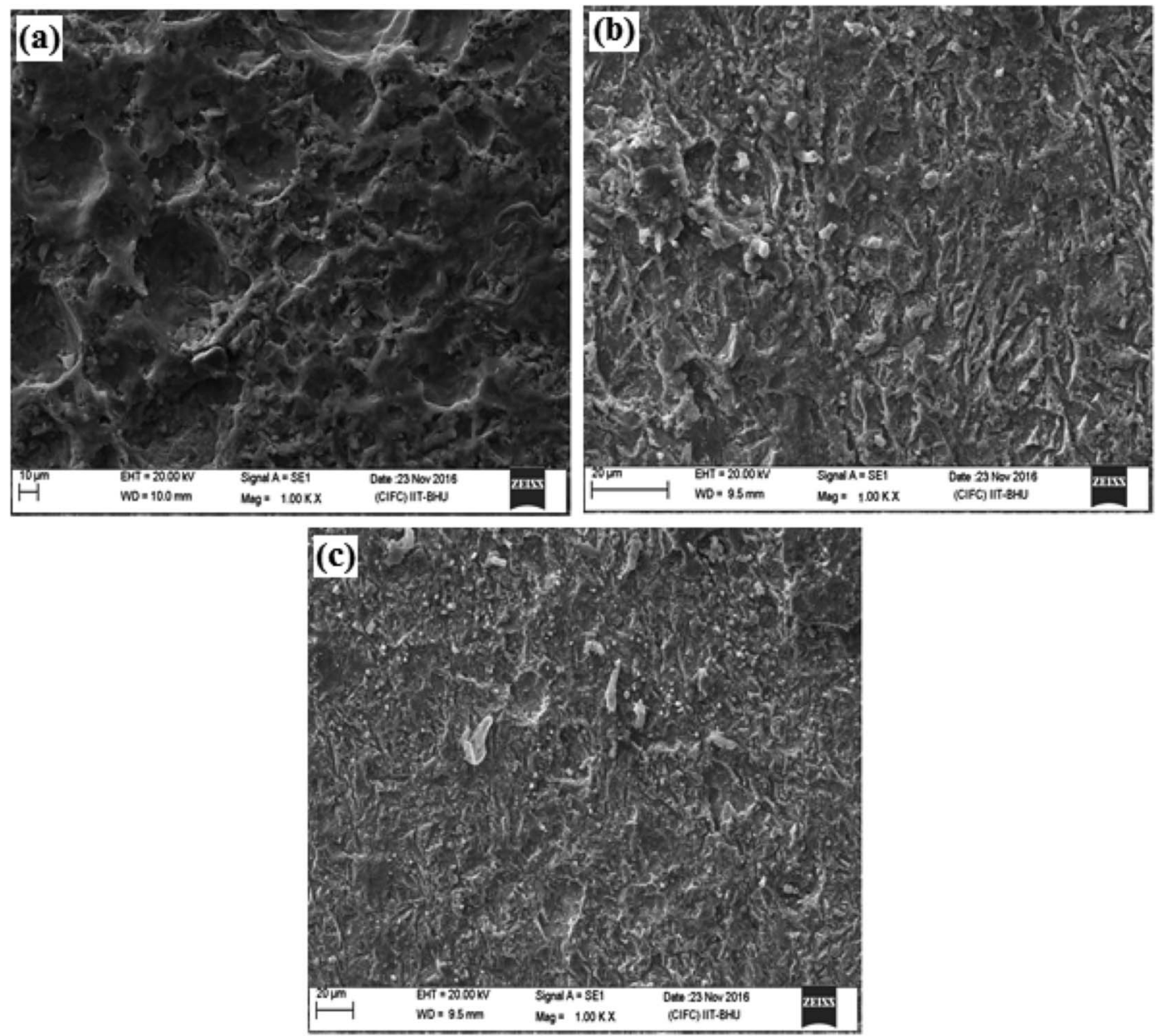

Fig. 6 SEM micrographs in the absence (a) and the presence of DAMP-GO (b) and DAZP-GO (c) after $3 \mathrm{~h}$ immersion time. 
Table 3 Some common DFT-based quantum chemical calculation indices derived for diaminopyridine and diazopyridine using Gaussian 09

\begin{tabular}{|c|c|c|c|c|c|c|c|}
\hline \multirow[b]{2}{*}{ Compounds } & \multicolumn{7}{|l|}{ Parameters } \\
\hline & $E_{\text {номо }}(\mathrm{eV})$ & $E_{\text {LUMO }}(\mathrm{eV})$ & $\Delta E(\mathrm{eV})$ & $\chi$ & $\eta$ & $\sigma$ & $\Delta N$ \\
\hline DAZP & -3.036 & -2.432 & 0.604 & 2.73 & 0.302 & 3.311 & 4.100 \\
\hline
\end{tabular}

and the results of this are shown in Fig. 8(a)-(d). The highresolution $\mathrm{C}$ 1s XPS spectrum of mild steel specimens with concentrations of $25 \mathrm{mg} \mathrm{L}^{-1}$ of DAZP-GO consists of four peaks as shown in Fig. 8(a). The first signal at a binding energy of $284.6 \mathrm{eV}$ is assigned to the $\mathrm{C}-\mathrm{C}$ of graphene and its analogs. The second signal at $285.3 \mathrm{eV}$ is attributed to the carbon atom
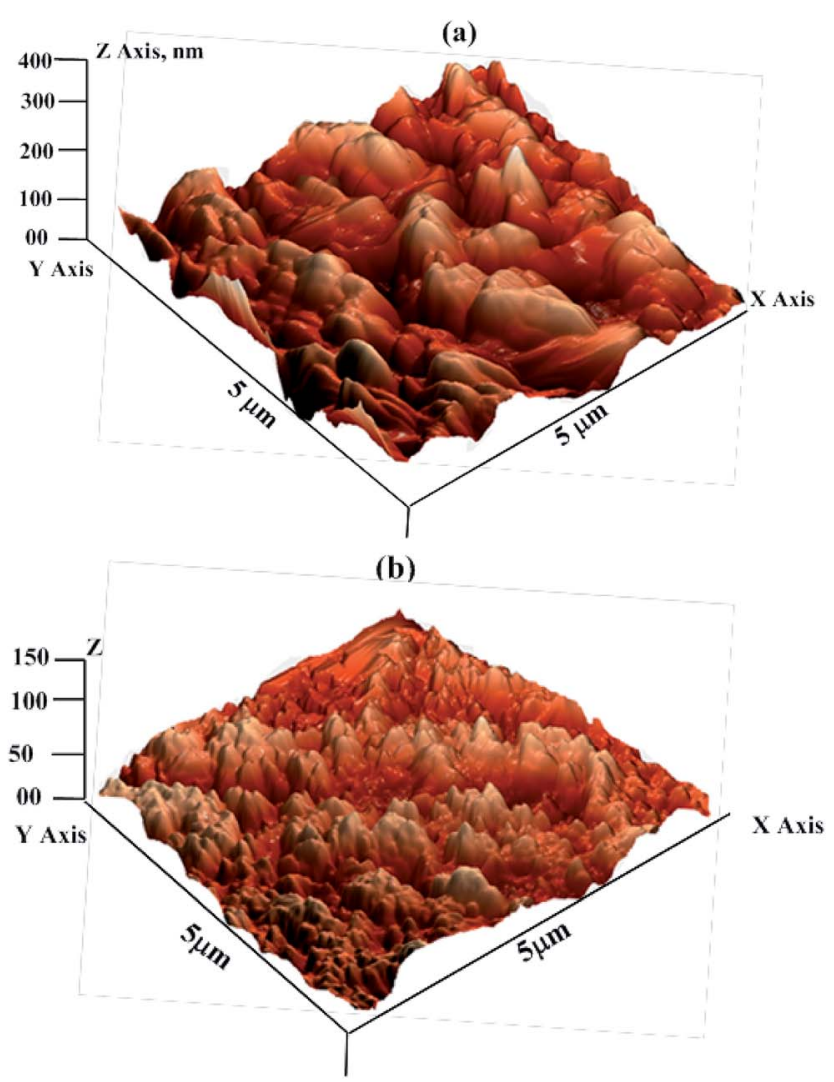

(c)

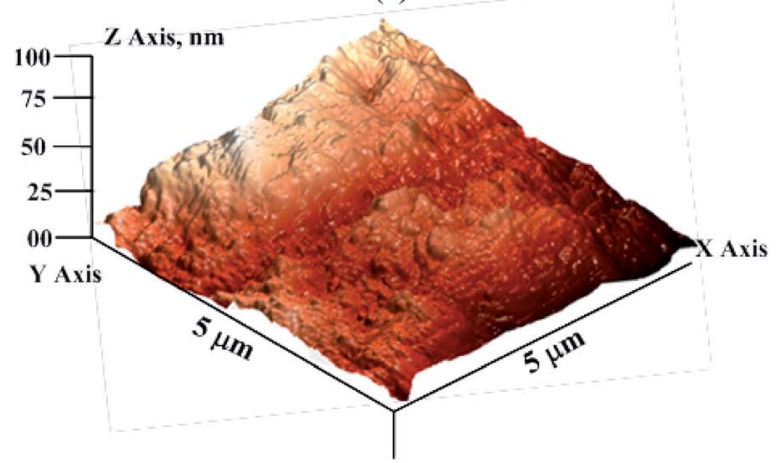

Fig. 7 AFM micrographs in the absence (a) and presence of DAMP-GO (b) and DAZP-GO (c) after $3 \mathrm{~h}$ immersion time. bonded to nitrogen in DAZP-GO. The third and fourth signal are attributed to the $\mathrm{C}-\mathrm{O}$ bond of the hydroxyl group $(\mathrm{C}-\mathrm{OH})$ and the presence of carboxylic group at $286.4 \mathrm{eV}$ and 288.6, respectively. ${ }^{22,24}$ The high-resolution $\mathrm{N}$ 1s XPS spectrum of mild steel specimens with concentrations of $25 \mathrm{mg} \mathrm{L}^{-1}$ of DAZP-GO consists of three peaks as shown in Fig. 8(b). The first signal shows a peak at $398.8 \mathrm{eV}$ from the nitrogen atoms of the DAZP ring bonded with the steel surface $(\mathrm{N}-\mathrm{Fe}) .{ }^{46}$ The second signal at $399.7 \mathrm{eV}$ in DAZP-GO results from the $\mathrm{C}-\mathrm{N}$ bonds and unprotonated $\mathrm{N}$ atoms in DAZP-GO. The signal at $400.4 \mathrm{eV}$ in DAZPGO is from the protonated nitrogen atoms in the DAZP ring. ${ }^{22}$ The O 1s XPS spectra for DAZP-GO adsorbed mild steel specimens fitted the three signals as shown in Fig. 8(c). The first signal at $530.3 \mathrm{eV}$ is attributed to $\mathrm{O}^{2-}$ and this is attributed to an oxygen atom bonded to $\mathrm{Fe}^{3+}$ in the $\mathrm{FeO}, \mathrm{Fe}_{2} \mathrm{O}_{3}$, and $\mathrm{Fe}_{3} \mathrm{O}_{4}$ oxides. The second signal observed at $531.6 \mathrm{eV}$ indicates the presence of $\mathrm{OH}^{-}$, which can associate with the occurrence of hydrous iron oxides, such as FeOOH. The third signal at $532.7 \mathrm{eV}$ indicates the presence of oxygen as an hydroxyl group $(\mathrm{C}-\mathrm{OH})$ in DAZP. ${ }^{46}$ The high-resolution Fe $2 \mathrm{p}$ XPS spectrum of mild steel specimens with concentrations of $25 \mathrm{mg} \mathrm{L}^{-1}$ of DAZP consists of three peaks which are shown in Fig. 8(d). The first signal at $710.2 \mathrm{eV}$ indicates the presence of $\mathrm{Fe}^{3+}$ in ferric compounds such as $\mathrm{Fe}_{2} \mathrm{O}_{3}$ and $\mathrm{FeOOH}$. The second signal at $711.7 \mathrm{eV}$ indicates the presence of a small concentration of $\mathrm{FeCl}_{3}$ on the mild steel surface. The signal at a $713.6 \mathrm{eV}$ indicates the presence of $\mathrm{Fe}(\mathrm{III}) .{ }^{46}$ The results obtained from XPS analysis support the adsorption of inhibitors on the mild steel surface.

3.2.4. Computational study. DFT is an important theoretical tool used to predict the inhibition efficiency of organic molecules and to correlate their molecular structure with efficiency. The optimized and frontier molecular orbital pictures of basic organic compounds of DAMP-GO (diaminopyridine) and DAZP-GO (diazopyridine) are shown in Fig. 9 and 10. Generally, HOMO and LUMO represent the electron donating and electron accepting tendency of the molecule. A molecule with a high value of HOMO energy ( $E_{\text {Номо }}$ ) is consistent with a high electron donating ability to the appropriate acceptor molecule and vice versa. Conversely, a molecule with lower value LUMO energy ( $\left.E_{\mathrm{LUMO}}\right)$ is consistent with a high electron accepting ability from the appropriate donor molecule. It is well established that adsorption of organic inhibitors over a metallic surface involves donor-acceptor interaction. It is postulated that organic inhibitors donate their bonding and non-bonding electrons to the d-orbital of the surface Fe atoms during metal-inhibitor interactions. ${ }^{47-49}$ However, metals are already electron rich species, and this type of electron donation causes inter- 

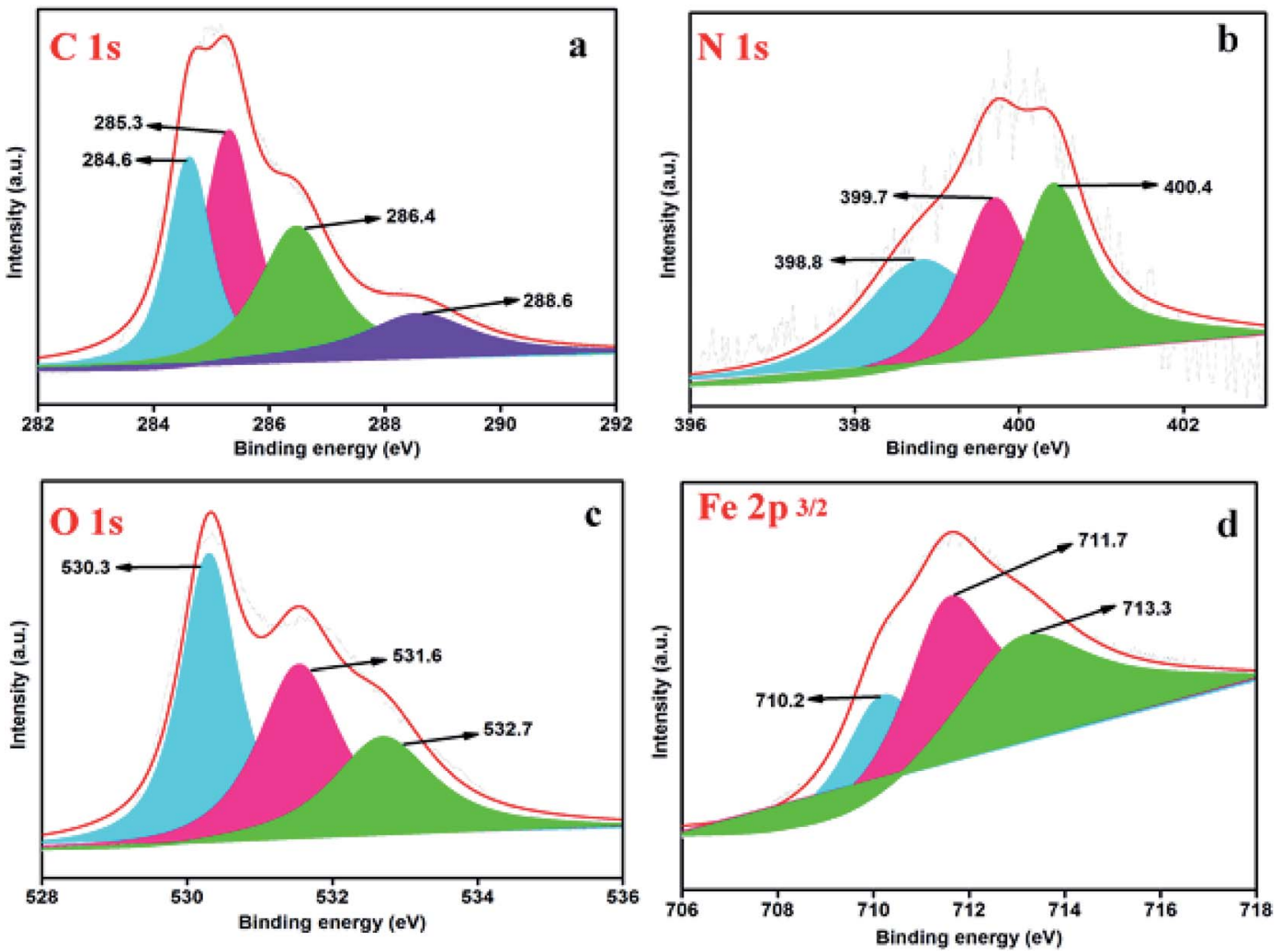

Fig. 8 (a) High-resolution $C$ 1s XPS spectrum of mild steel specimens with DAZP-GO inhibitor, (b) high-resolution N 1s XPS spectrum of mild steel specimens with DAZP-GO inhibitor, (c) high-resolution O 1s XPS spectrum of mild steel specimens with DAZP-GO inhibitor, (d) highresolution Fe 2p XPS spectrum of mild steel specimens with DAZP-GO inhibitor.

electronic repulsion, which further causes the transfer of an electron from metal to an anti-bonding molecular orbital of the inhibitor molecule. This type of electron transfer is known as retro-donation. Both donation and retro-donation occur simultaneously during metal-inhibitor interaction and strengthen each other through synergism. ${ }^{50-55}$ Therefore, an inhibitor with a higher value of $E_{\text {Номо }}$ and a lower value of $E_{\mathrm{LUMO}}$ favors strong adsorption and inhibition efficiency. The energy band gap is another reactivity parameter, which can be used to predict the chemical reactivity and adsorption tendency of the inhibitor molecule. Generally, a compound with a lower value of $\Delta E$ is associated with high chemical reactivity and thereby acts as an efficient corrosion inhibitor. In the present study, values of $E_{\mathrm{HOMO}}, E_{\mathrm{LUMO}}$ and $\Delta E$ suggest that diazopyridine acts as a better corrosion inhibitor when compared to diaminopyridine and this agreed well with the experimental order of inhibition efficiency. ${ }^{56,57} \mathrm{~A}$ hard molecule has a lower
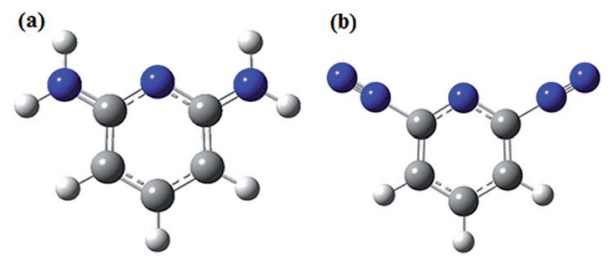

Fig. 9 Optimized structure of (a) diaminopyridine (b) diazopyridine. chemical reactivity and therefore a lower inhibition efficiency. The values of hardness follow the order: diazopyridine $(0.302$ $\mathrm{eV})<$ diaminopyridine $(2.559 \mathrm{eV})$ indicating that diazopyridine is a softer molecule and acts as better inhibitor when compared to diaminopyridine. In contrast, a softer molecule is related to a high chemical reactivity, and therefore a compound with high softness is consistent with a high chemical reactivity and therefore a high inhibition efficiency. In the present case, the value of softness follows the order: diazopyridine (3.311) > diaminopyridine (0.391) which is in accordance with the order of inhibition efficiency obtained by experimental methods.

(a)

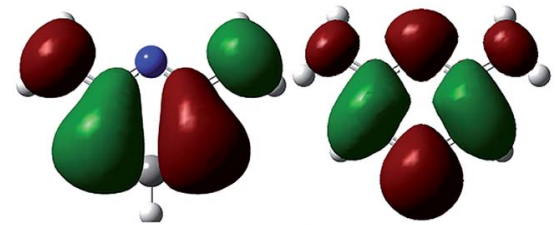

(b)

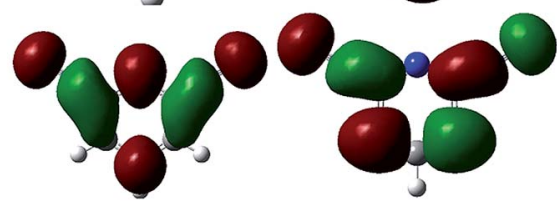

Fig. 10 Frontier molecular electron distribution of (a) diaminopyridine (b) diazopyridine; highest occupied molecular orbitals (left) and right lowest unoccupied molecular orbitals (right). 
Lastly, a higher value of electron transfer $(\Delta N)$ for diazopyridine (4.100) when compared to diaminopyridine (0.375) indicates that the former is a better corrosion inhibitor than the latter. In summary, it can be concluded that both experimental and theoretical methods showed that the inhibition efficiency of the tested compounds follows the order: DAMP-GO (diaminopyridine) < DAZP-GO (diazopyridine).

\section{Conclusions}

The present study involves the synthesis of two functionalized GOs. Namely, diazopyridine functionalized graphene oxide (DAZP-GO) and diaminopyridine functionalized graphene oxide (DAMP-GO) and their characterization using FT-IR, XRD, Raman, XPS and TEM methods. The inhibitive action of these functionalized GO was evaluated in $1 \mathrm{M} \mathrm{HCl}$ solution using several techniques. The following conclusions were drawn:

(1) Both the functionalized GO act as superior corrosion inhibitors and their inhibition efficiency increases with their concentrations. The maximum inhibition efficiencies of $95.06 \%$ and $96.73 \%$ were obtained for DAMP-GO and DAZP-GO, respectively, at a concentration as low as $25 \mathrm{mg} \mathrm{L}^{-1}$.

(2) The EIS results showed that DAMP-GO and DAZP-GO inhibits corrosion by adsorption on the metallic surface, thus forming a protective barrier.

(3) The results of a potentiodynamic polarization study showed that both functionalized GOs acted as mixed type corrosion inhibitors.

(4) The results of the SEM and AFM studies suggest that surfaces of the inhibited metallic specimens become smoother when compared to the surface of the uninhibited metallic specimen which results in the adsorption and formation of the protective barrier by the functionalized GOs which protect the metal from corrosion. The formation of a protective film was further supported by the results of the EDX spectroscopic analysis where significant enhancement in the signal for nitrogen was observed with the inhibited metallic specimens.

(5) Adsorption of the tested functionalized GO on the metallic surface was further supported by the results of the XPS analysis.

(6) Experimental results were supported by DFT-based quantum chemical calculations. Several derived DFT-based parameters such as $E_{\mathrm{HOMO}}, E_{\mathrm{LuMO}}, \Delta E, \chi, \sigma, \eta$, and $\Delta N$ validated the experimentally determined order of inhibition efficiency.

\section{Acknowledgements}

RKG, NKG and CV, thankfully acknowledge the Government of India, Ministry of Human Resource Development (MHRD), New Delhi for providing funding.

\section{References}

1 R. Javaherdashti, Anti-Corros. Methods Mater., 2000, 47, 3034.
2 G. Koller, U. Fischer and K. Hungerbühler, Ind. Eng. Chem. Res., 2000, 39, 960-972.

3 G. Hamer, Biotechnol. Adv., 2003, 22, 71-79.

4 G. H. Koch, J. Varney, N. G. Thompson, O. Moghissi, M. Gould and J. Payer, International Measures of Prevention, Application, and Economics of Corrosion Technologies Study, NACE International, Houston, TX, 2016, pp. 2-6.

5 G. H. Koch, in Historic Congressional Study: Corrosion Costs And Preventive Strategies, The United States, 2002.

6 G. Gece, Corros. Sci., 2008, 50, 2981-2992.

7 F. Mansfeld, Electrochim. Acta, 1990, 35, 1533-1544.

8 M. Ormellese, L. Lazzari, S. Goidanich, G. Fumagalli and A. Brenna, Corros. Sci., 2009, 51, 2959-2968.

9 E. Sherif and S.-M. Park, Corros. Sci., 2006, 48, 4065-4079.

10 A. Ylldırım and M. Cetin, Corros. Sci., 2008, 50, 155-165.

11 E. Oguzie, Y. Li and F. Wang, J. Colloid Interface Sci., 2007, 310, 90-98.

12 S. Umoren and E. Ebenso, Mater. Chem. Phys., 2007, 106, 387-393.

13 F. Bentiss, M. Traisnel and M. Lagrenee, J. Appl. Electrochem., 2001, 31, 41-48.

14 E. M. Fayyad, K. K. Sadasivuni, D. Ponnamma and M. A. AlMaadeed, Carbohydr. Polym., 2016, 151, 871-878.

15 N. Kirkland, T. Schiller, N. Medhekar and N. Birbilis, Corros. Sci., 2012, 56, 1-4.

16 D. Prasai, J. C. Tuberquia, R. R. Harl, G. K. Jennings and K. I. Bolotin, ACS Nano, 2012, 6, 1102-1108.

17 J. Mondal, M. Marandi, J. Kozlova, M. Merisalu, A. Niilisk and V. Sammelselg, J. Chem. Chem. Eng., 2014, 8, 786-793.

18 B. Ramezanzadeh, S. Niroumandrad, A. Ahmadi, M. Mahdavian and M. M. Moghadam, Corros. Sci., 2016, 103, 283-304.

19 A. B. Ikhe, A. B. Kale, J. Jeong, M. J. Reece, S.-H. Choi and M. Pyo, Corros. Sci., 2016, 109, 238-245.

20 J. Mondal, M. Kozlova and V. Sammelselg, J. Nanosci. Nanotechnol., 2015, 15, 6747-6750.

21 K. Chang, W. Ji, C. Li, C. Chang, Y. Peng, J. Yeh and W. Liu, eXPRESS Polym. Lett., 2014, 8, 908-919.

22 A. Gupta, B. K. Shaw and S. K. Saha, RSC Adv., 2014, 4, 50542-50548.

23 D. Dinda and S. K. Saha, J. Hazard. Mater., 2015, 291, 93-101. 24 A. Gupta, B. K. Shaw and S. K. Saha, J. Phys. Chem. C, 2014, 118, 6972-6979.

25 A. Gupta and S. K. Saha, Nanoscale, 2012, 4, 6562-6567.

26 C. Verma, M. Quraishi and A. Singh, J. Taiwan Inst. Chem. Eng., 2016, 58, 127-140.

27 C. Verma, M. Quraishi and E. Ebenso, Int. J. Electrochem. Sci., 2013, 8, 10851-10863.

28 A. D. Becke, J. Chem. Phys., 1993, 98, 5648-5652.

29 C. Verma, L. Olasunkanmi, I. Obot, E. E. Ebenso and M. Quraishi, RSC Adv., 2016, 6, 15639-15654.

30 A. D. Becke, Phys. Rev. A, 1988, 38, 3098.

31 C. Verma, M. Quraishi, L. Olasunkanmi and E. E. Ebenso, RSC Adv., 2015, 5, 85417-85430.

32 C. Lee, W. Yang and R. G. Parr, Phys. Rev. B: Condens. Matter Mater. Phys., 1988, 37, 785. 
33 D. K. Singh, V. Kumar, V. K. Singh and S. H. Hasan, RSC Adv., 2016, 6, 56684-56697.

34 P. Singh, E. E. Ebenso, L. O. Olasunkanmi, I. B. Obot and M. A. Quraishi, J. Phys. Chem. C, 2016, 120, 3408-3419.

35 L. O. Olasunkanmi, I. B. Obot, M. M. Kabanda and E. E. Ebenso, J. Phys. Chem. C, 2015, 119, 16004-16019.

36 C. Verma, E. E. Ebenso, L. O. Olasunkanmi, M. A. Quraishi and I. B. Obot, J. Phys. Chem. C, 2016, 120, 11598-11611.

37 J. Haque, V. Srivastava, C. Verma and M. Quraishi, J. Mol. Liq., 2017, 225, 848-855.

38 R. Solmaz, G. Kardaş, M. Culha, B. Yazıcı and M. Erbil, Electrochim. Acta, 2008, 53, 5941-5952.

39 M. Erbil, Chim. Acta Turc., 1988, 1, 59-70.

40 A. Yousefi, S. Javadian, N. Dalir, J. Kakemam and J. Akbari, RSC Adv., 2015, 5, 11697-11713.

41 C. Verma, A. Singh, G. Pallikonda, M. Chakravarty, M. Quraishi, I. Bahadur and E. Ebenso, J. Mol. Liq., 2015, 209, 306-319.

42 A. B. Ikhe, A. B. Kale, J. Jeong, M. J. Reece, S.-H. Choi and M. Pyo, Corros. Sci., 2016, 109, 238-245.

43 R. Yıldız, T. Doğan and I. Dehri, Corros. Sci., 2014, 85, 215221.

44 P. Mourya, S. Banerjee and M. Singh, Corros. Sci., 2014, 85, 352-363.

45 P. Singh and M. Quraishi, Measurement, 2016, 86, 114-124.
46 P. Singh, V. Srivastava and M. Quraishi, J. Mol. Liq., 2016, 216, 164-173.

47 T. Arslan, F. Kandemirli, E. E. Ebenso, I. Love and H. Alemu, Corros. Sci., 2009, 51, 35-47.

48 I. Obot and Z. Gasem, Corros. Sci., 2014, 83, 359-366.

49 I. Obot and N. Obi-Egbedi, Corros. Sci., 2010, 52, 657-660.

50 S. Yesudass, L. O. Olasunkanmi, I. Bahadur, M. M. Kabanda, I. Obot and E. E. Ebenso, J. Taiwan Inst. Chem. Eng., 2016, 64, 252-268.

51 M. ElBelghiti, Y. Karzazi, A. Dafali, B. Hammouti, F. Bentiss, I. Obot, I. Bahadur and E. Ebenso, J. Mol. Liq., 2016, 218, 281-293.

52 L. C. Murulana, M. M. Kabanda and E. E. Ebenso, J. Mol. Liq., 2016, 215, 763-779.

53 L. O. Olasunkanmi, M. M. Kabanda and E. E. Ebenso, Phys. E, 2016, 76, 109-126.

54 A. Khadiri, R. Saddik, K. Bekkouche, A. Aouniti, B. Hammouti, N. Benchat, M. Bouachrine and R. Solmaz, J. Taiwan Inst. Chem. Eng., 2016, 58, 552-564.

55 A. Döner, R. Solmaz, M. Özcan and G. Kardaş, Corros. Sci., 2011, 53, 2902-2913.

56 I. Obot, D. Macdonald and Z. Gasem, Corros. Sci., 2015, 99, 1-30.

57 N. O. Eddy, H. Momoh-Yahaya and E. E. Oguzie, J. Adv. Res., 2015, 6, 203-217. 